\title{
Methods for the Preparation of Modified Polyorganosiloxanes (A Review)
}

\author{
KOSTYUKOVICH ALEXANDERYUR'EVICH' ${ }^{1}$, DROZDOV FEDOR VALER'EVICH ${ }^{2}$, \\ VITALY SERGEEVICH IVANOV ${ }^{1}$, ANTON SERGEEVICH YEGOROV ${ }^{1 *}$ and \\ VLADIMIR VIKTOROVICH MEN'SHIKOV'.
}

${ }^{1}$ The Federal State Unitary Enterprise «Institute of Chemical Reagents and High Purity Chemical Substances of National Research Centre «Kurchatov Institute» (NRC «Kurchatov Institute» - IREA.) 107076, Bogorodsky val, 3. Moscow. Russia.

${ }^{2}$ Enikolopov Institute of Synthetic Polymeric Materials, a foundation of the Russian Academy of Sciences (ISPM RAS) 117393, Profsoyuznaya st. 70, Moscow, Russia.

${ }^{\star}$ Corresponding author E-mail: egorov@irea.org.ru

http://dx.doi.org/10.13005/ojc/340202

(Received: December 29, 2017; Accepted: March 01, 2018)

\section{ABSTRACT}

The review presents the main methods for the preparation of modified polyorganosiloxanes (POS) containing amino groups. Modified POS are the most important functional compounds for the synthesis of polyimide and polysiloxane copolymers used as a material for polymeric electrolytic membranes (PEM) of fuel cells (FC). The reactions of cationic and anionic polymerization, hydrosilylation, condensation of chlorosilanes are considered. The main advantages and disadvantages of these methods are discussed.

Keywords: Modified polysiloxanes, Polyimides, Copolymers, Fuel cell, Polymeric membrane.

\section{INTRODUCTION}

The fuel cell is one of the most promising alternative energy sources. ${ }^{1-3}$ Its necessary detail is a polymeric electrolytic membrane, which carries out selective and one-way proton transport. The role of PEM is to effectively separate electrodes in $\mathrm{FC}$ in order to prevent both a direct chemical reaction of the molecular reagents and direct electrical contact of the electrodes while providing unimpeded proton transport from the anode to the cathode. ${ }^{4-7}$ From the peculiarities of PEM work in FC it follows that PEM materials shall be resistant primarily to the main $\mathrm{FC}$ components-water and methanol, as well as to the possible by products-hydrogen peroxide. In addition, it is necessary that the chemical resistance of such materials is maintained throughout the whole FC 
operating life. The necessity of fulfilling all of the above requirements by one PEM means that for highly efficient FC operation it is necessary to develop PEM of a block structure (block copolymers) in which each repeating polymer block fulfills a certain function, which together leads to satisfaction of all declared characteristics. ${ }^{8-11}$

One of the most promising candidates to be used as PEM for FC is copolymers of sulfonated polyimides, which can form a closely packed microstructure with controlled permeability, ${ }^{12-16}$ and polyorganosiloxanes that improve the physical and mechanical properties of the polyimide matrix. ${ }^{17}$ As a rule, these copolymers are obtained by stepwise polymerization of diamines with dianhydrides of aromatic tetracarboxylic acids. ${ }^{18,19}$

Polyorganosiloxanes with amino endgroups are the most important functional compounds for the synthesis of polyimide and polysiloxane copolymers. ${ }^{20}$ However, it should be specially noted that the direct introduction of the silazane group into the POS structure is not very promising due to the propensity to hydrolysis and formation of cyclic adducts. This behavior is explained by the low binding energy of $\mathrm{Si}-\mathrm{N}$ in linear organic polymers. Linker groups between the amino group and the siloxane fragment are introduced to circumvent such difficulties. These groups usually include alkyl and aryl fragments.

Introduction of the amino group into the POS structure is often complicated by its properties such as

- $\quad$ reaction capacity with respect to the starting reagents, POS structure, catalysts;

- basicity (this factor may cause the Si-O bond cleavage);

ability to act as a ligand in the reactions of metal complex catalysis, suppressing the catalyst action.

There are four main strategies for the aminosiloxane synthesis

- $\quad$ hydrosilylation reaction; bonding the $\mathrm{Si}-\mathrm{H}$ bond of POS to a double bond of a compound containing an amino group;

- combination of a bifunctional organosilicon compound with another organoelemental compound containing a protected amino group;

POS functionalization with nitrogencontaining groups with their subsequent reduction to amino groups;

opening of cyclosiloxanes by diaminooligosiloxanes followed by stepwise polymerization.

Methods for implementing these strategies are presented in this review.

\section{Ways to prepare polyorganosiloxanes}

Both in industry and in the laboratory, linear POS is obtained in two ways: by stepwise polymerization of bifunctional organosilicon derivatives of $\mathrm{R}_{2} \mathrm{SiX}_{2}$ and by polymerization methods (anionic or cationic polymerization, ring-opening polymerization). Choice of the method for preparing POS is determined by several factors. ${ }^{21,22}$

First factor is the dependence of the molecular-mass parameters of the polymer on the mechanism of the reaction carried out. For example, as a result of the stepwise polymerization reaction under equilibrium conditions, the molecular-mass distribution (MMD) of the polymer prepared is much wider than in the case of polymerization reactions, and the polydispersity index (PDI) for such a polymer is greater than 2 . If it is necessary to obtain a desired polymer with a narrow MMD, it is necessary either to obtain the polymer by the polymerization reaction or to fractionate the polymer prepared by the stepwise polymerization reaction, which often involves certain difficulties.

The second factor is related to the reaction conditions. It often happens that polymers prepared by the same type of polymerization with the same structure vary enormously in molecular-mass characteristics. Reason for such phenomena may be a large number of factors affecting the course of polymerization: temperature, concentration, mixing speed, nature and purity of solvents and starting monomers, reaction time, presence of foreign impurities. In addition to these factors, the nature of polymerization initiator and the choice of starting monomers play a huge role. 
Preparation of polyorganosiloxanes by the cationic polymerization method

Cationic polymerization of dialkoxysiloxane or cyclosiloxane monomers is most often used to prepare siloxane oligomers and low molecular weight polymers. Protonic acids $\left(\mathrm{H}_{2} \mathrm{SO}_{4}, \mathrm{HClO}_{4}\right.$, $\left.\mathrm{CF}_{3} \mathrm{SO}_{3} \mathrm{H}\right)$ or Lewis acids are used as the initiator (Figure 1). ${ }^{23-25}$

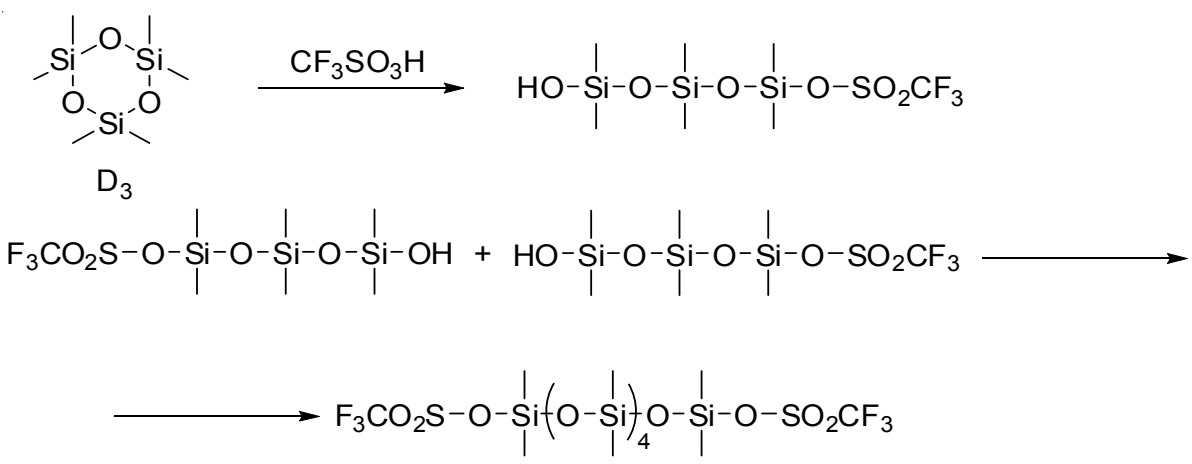

Fig. 1. Synthesis of low molecular weight POS by the cationic polymerization method with ring opening

Convenient method is acidolysis condensation, consisting in the opening of cyclosiloxane derivatives (usually $\mathrm{D}_{3}$ or $\mathrm{D}_{4}$ ) by acid. ${ }^{26,27}$ In the early stages of conversion, there are formed oligomers which chain length corresponds to the one of the open cyclosiloxanes. Siloxane chains of such linear oligosiloxanes contain, respectively, a silanol $(\mathrm{Si}-\mathrm{OH})$ and a functionalized Si-A group. If in early stages the reactive silanol group is blocked to prevent further polymerization, the oligomers prepared with the $\mathrm{Si}-\mathrm{A}$ functional group can be isolated in an individual state and used for further modifications. For example, if $D_{3}$ is opened by trifluorosulfonic acid, blocking the silanol group in the early stages of polymerization with trimethylchlorosilane, monofunctional oligosiloxanes containing a reactive trifluorosulfonic group can be isolated (Figure 2a).

a)

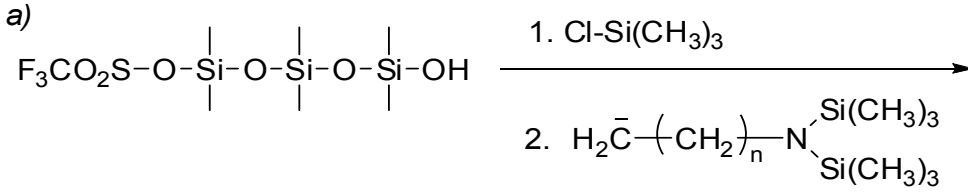

$$
\begin{aligned}
& \text { 3. } \mathrm{H}_{2} \mathrm{O}
\end{aligned}
$$

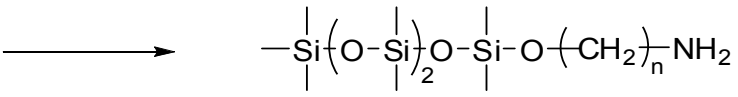

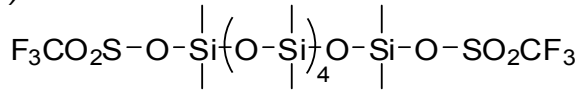

$$
\begin{aligned}
& \frac{\text { 1. } \mathrm{H}_{2} \overline{\mathrm{C}}-\left(\mathrm{CH}_{2}\right)_{\mathrm{n}}-\mathrm{N}_{\mathrm{Si}\left(\mathrm{CH}_{3}\right)_{3}}^{\mathrm{Si}\left(\mathrm{CH}_{3}\right)_{3}}}{\text { 2. } \mathrm{H}_{2} \mathrm{O}}
\end{aligned}
$$

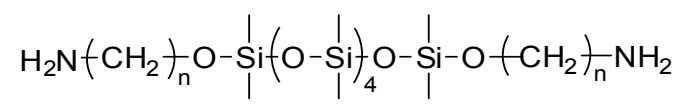

Fig. 2. Methods for the modification of oligomers prepared by the acidolysis condensation of cyclosiloxane 
On the other hand, polymerization can be carried out to form final products containing a trifluorosulfonic group at both ends of the chain and then modify the oligomers by nucleophilic substitution (Figure 2b).

Cationic polymerization is a convenient method for preparing oligomeric POS with functional end groups that can be both blocked and functionalized. Since the end groups have different reactivity, cationic polymerization opens up great possibilities for further siloxane chain modifications. In addition, using chloromethylene, vinylic or other functionalized siloxanes as monomers, further modification of the side chain of prepared POS is possible.

Preparation of polyorganosiloxanes by the anionic polymerization method

Anionic polymerization is used to prepare high molecular weight POS with narrow MMD. Often,

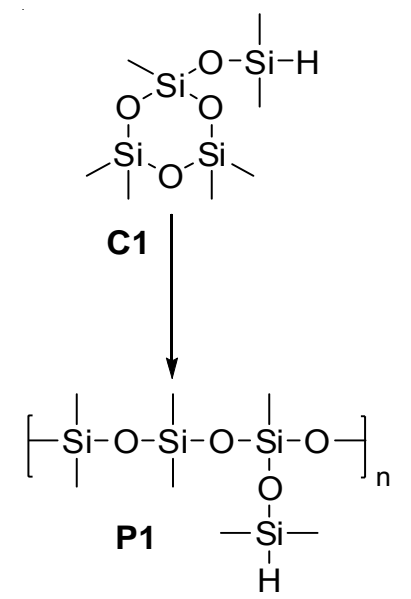

it is used to obtain POS of block, alternating structure, using functionalized cyclosiloxanes. ${ }^{28-32}$ However, anionic polymerization is complicated by its conditions. This method is extremely sensitive to the inertness of medium, the purity of reagents and solvents, and the presence of impurities. Therefore, this method is expensive in comparison with other types of polymerization, however, the polymers prepared by anionic polymerization outperform the analogues in terms of molecular-mass characteristics. ${ }^{33}$ Various nucleophilic initiators are used in the case of anionic ring-opening polymerization: organo-metal compounds, alkoxides, silicates, etc. The anionic ring-opening polymerization method makes it possible to prepare a variety of alternating POS by varying the functional groups in the structure of the starting cyclosiloxanes. As an example, one can take POS of a regular structure prepared by anionic polymerization under identical conditions, but based on different cyclotrisiloxane derivatives (Figure 3).<smiles>[R2][Si](C)(C)O[Si](C)(C)O[Si](C)(O[Si](C)(C)C)O[Si](C)(C)O[Si](C)(C)O[Si](C)(C)O[Si](C)(C)C</smiles>

Fig. 3. Preparation of POS of a various structures by an anionic ring-opening polymerization

From the data of the molecular-mass distribution (Table 1), it is evident that $M_{n}$ for $P 2$ polymer is almost 3 times larger than P1, which is possibly associated with steric hindrance arising from the opening of $\mathrm{C} 1$ cycle as compared to $\mathrm{C} 2 .^{34,35}$

Table 1: Molecular-mass characteristics and glass transition temperature $\left(T_{g}\right)$ of prepared $P 1$ and $P 2$ polymers

\begin{tabular}{lcccc}
\hline POS & $M_{n}$ & $M_{w}$ & PDI & $T_{g}, p C$ \\
\hline P1 & 4120 & 6060 & 1.47 & -131 \\
P2 & 11810 & 17890 & 1.51 & -120 \\
\hline
\end{tabular}


However, close values of polydispersity indices (PDI) indicate the similarity of polymerization processes in both situations. This fact suggests that the MMD of polymers is determined only by the position of substituents, and not by the conditions of polymerization. The difference in MMD of P1 and $\mathrm{P} 2$ polymers and the position of substituents in turn affects the physical parameters, in this case, the glass transition temperature. In the case of P2 polymer, $\mathrm{T}_{\mathrm{g}}$ decreased by $11^{\circ} \mathrm{C}$.

It is interesting to note that using anionic ring-opening polymerization, it is possible to prepare POS with a various polymer chain structure. Alternation of siloxane blocks of different functionality depends on the structure of the starting modified cyclosiloxane (Figure 4).<smiles>[X][Si]1(C)O[Si](C)(C)O[Si](C)(C)O1</smiles><smiles>[X][Si]1(C)O[Si](C)(C)O[Si](C)(C)O1</smiles><smiles>[X][Si]1(C)O[Si]([X])(C)O[Si](C)(C)O1</smiles><smiles>[X][Si]1(C)O[Si]([X])(C)O[Si]([X])(C)O1</smiles><smiles>[X][Si]1([X])O[Si]([X])([X])O[Si]([X])([X])O1</smiles>

block copolymer
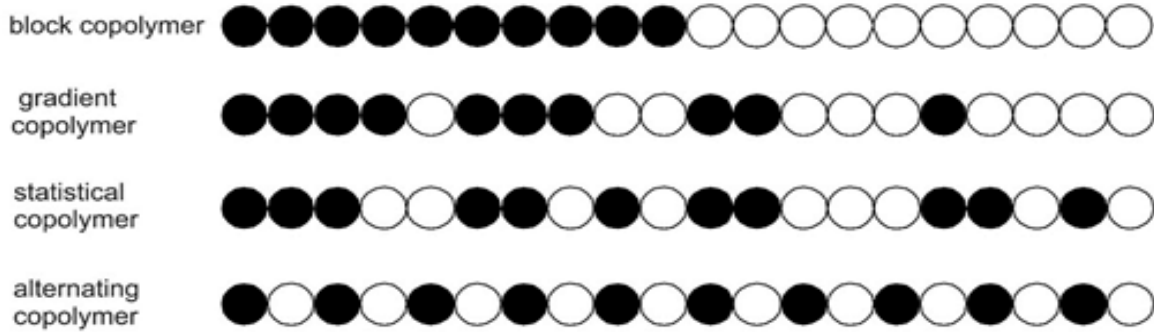

Fig. 4. Various functionalized cyclosiloxanes and structures of block copolymer chain

Bifunctional cyclosiloxanes with identically substituted silicon atoms are readily prepared from the corresponding dichlorosilanes acting on them with zinc oxide (Figure 5). ${ }^{36}$

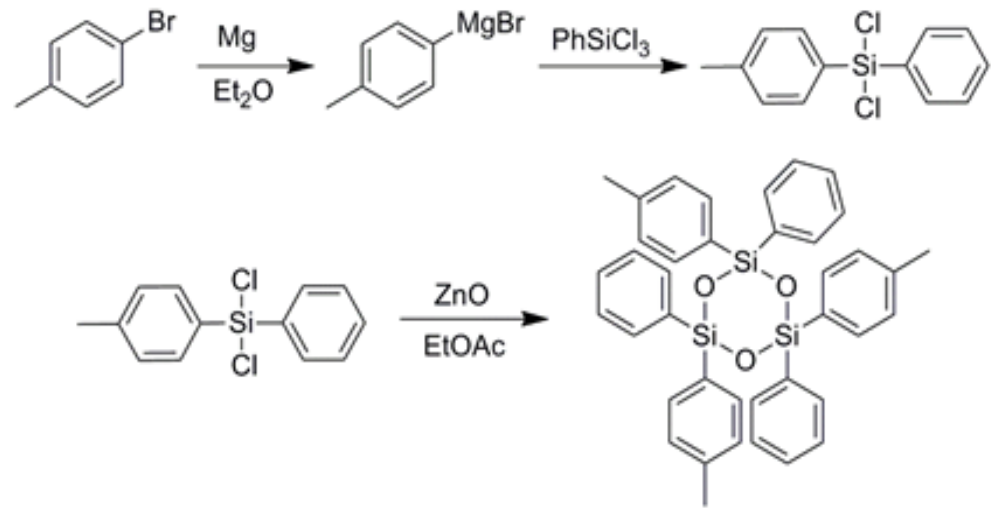

Fig. 5. Preparation of bifunctional cyclosiloxane with identically substituted silicon atoms

Asymmetrical bifunctional cyclosiloxanes are prepared by co-condensation of the corresponding bifunctional or monofunctional dichlorosilanes with diols or disilanols (Figure 6).
Double ring-opening copolymerization is also used in addition to anionic single cyclosiloxane opening polymerization. This results in block copolymers with units from different cycles (Figure 7). ${ }^{37}$ 


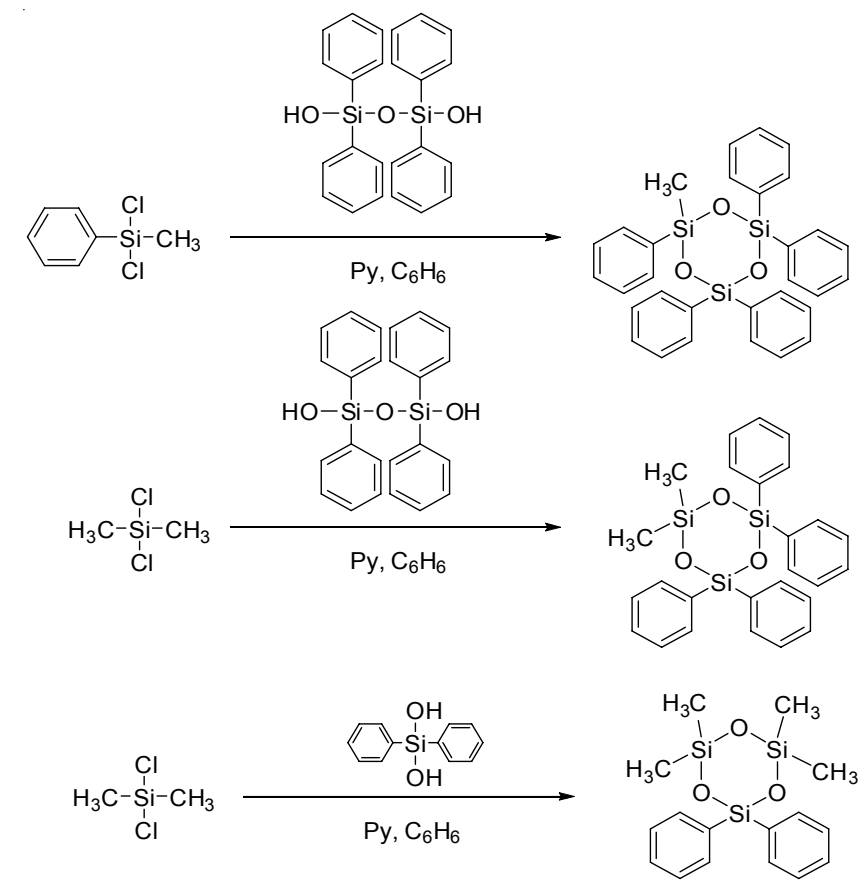

Fig. 6. Preparation of asymmetrical bifunctional cyclosiloxanes

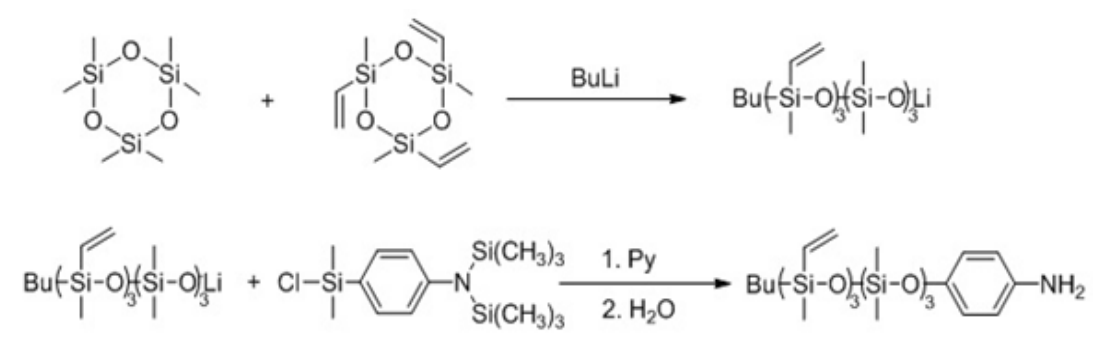

Fig. 7. Anionic copolymerization of two cyclosiloxanes

Polyorganosiloxanes modification by various chemical methods

Polymerization methods considered are effective and well-developed methods for preparation functional POS. With their help it is possible to synthesize directly modified POS, differing by substituents, molecular mass and alternation of units. However, it is often necessary to encounter difficulties in preparing suitable monomers. Low stability, the complexity of purification and isolation in an individual state of starting compounds for polymerization are the factors that greatly complicate the POS synthesis. ${ }^{38}$ Thus, for example, the disalanolic monomers necessary for the POS synthesis by the stepwise polymerization method are stable only if certain substituents stabilizing the $\mathrm{Si}-\mathrm{OH}$ bond are present in their structure, so it is certainly impossible to prepare POS with any substituents by this method. Another characteristic example is chlorosilanes, usually prepared from tetrachlorosilane by substituting a certain number of chlorine atoms for functional groups. As a result of such reactions, usually a mixture of products of different degree of substitution is prepared, and frequent proximity of their boiling points leads to the need for a long process of purification by rectification, which greatly complicates the process of preparing POS based on them and makes it more expensive. 
Therefore, polymer functionalization approaches are used in cases where it is necessary to prepare functional POS that can not be easily prepared directly by polymerization methods. In more detail, synthetic approaches for the introduction of functional groups into the chain of available POS are exemplified by the introduction of an amino group. ${ }^{39}$

Since POS is of interest with functional amino groups capable of further stepwise polymerization reactions to prepare a polyimide structure, we formulate the requirements for such compounds:

a) Chemical stability of functionalized POS. Amino groups that are part of the POS structure shall, for an unlimited period, be in the starting state under appropriate inert conditions, without reacting with solvents and the POS structure. On the other hand, such amino groups shall have sufficient reactivity for further use. b) Considered POS with functional amino groups are necessary for the further preparation of polyimides, therefore the range of modifiers under consideration is narrowed to alkylamines, arylamines and modified cyclic imides, which can be used directly in the polyimide synthesis.

c) Chemical reactions necessary for the POS modification shall not affect the POS chain and other functional groups included in its composition.

\section{Polyorganosiloxanes modification by hydrosilylation method}

Hydrosilylation allows the hydride-containing organosilicon compound to be grafted with a wide variety of functional groups linked by a double or triple bond. ${ }^{40,41}$ Hydrosilylation can be carried out stepwise, which allows us to gradually increase the POS structure (Figure 8).

With the help of hydrosilylation, it is possible to first functionalize cyclosiloxane and then open it with one of the polymerization types (Figure 9)

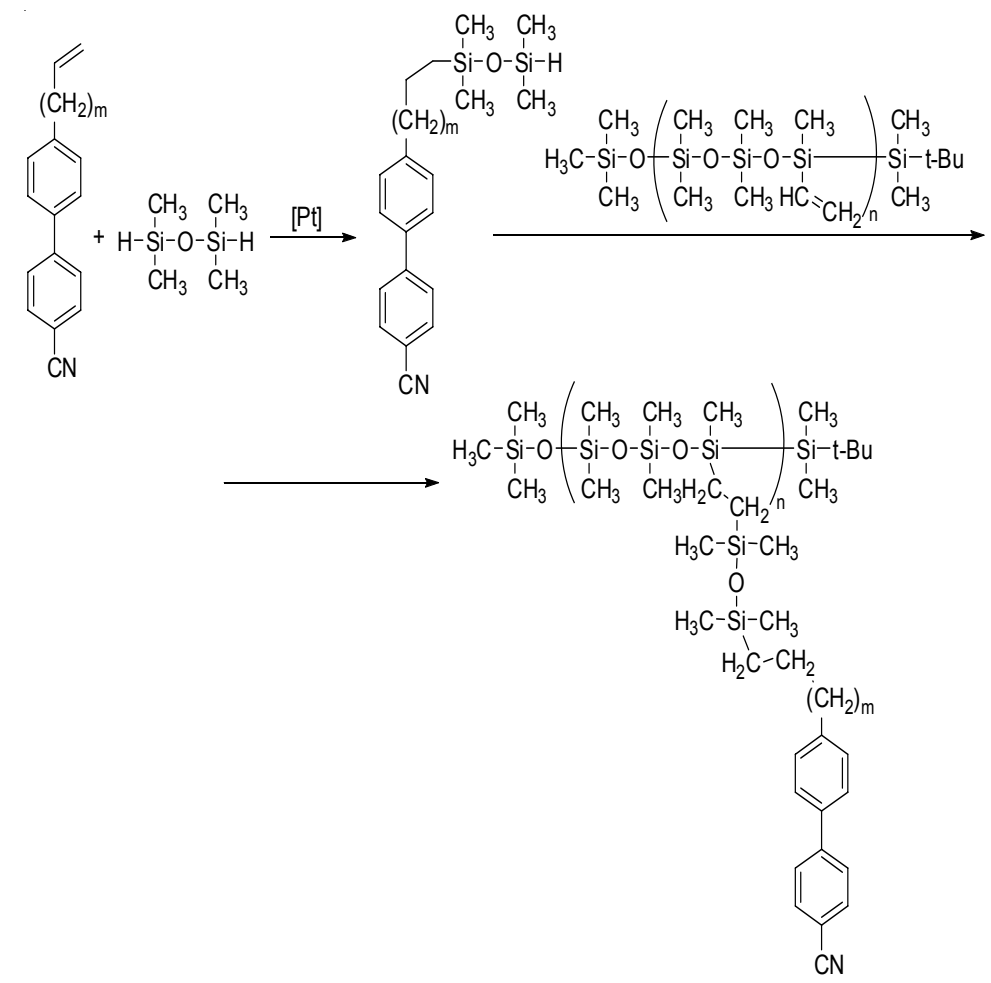

Fig. 8. Side chain graft to the POS by hydrosilylation 
<smiles>C[Si]1(C)O[Si](C)(C)O[Si](C)(C)O[Si](C)(C)O1</smiles><smiles>C=CCN</smiles><smiles>C[Si]1(C)O[Si](C)(C)O[Si](C)(C)O[Si](C)(C)O1</smiles>

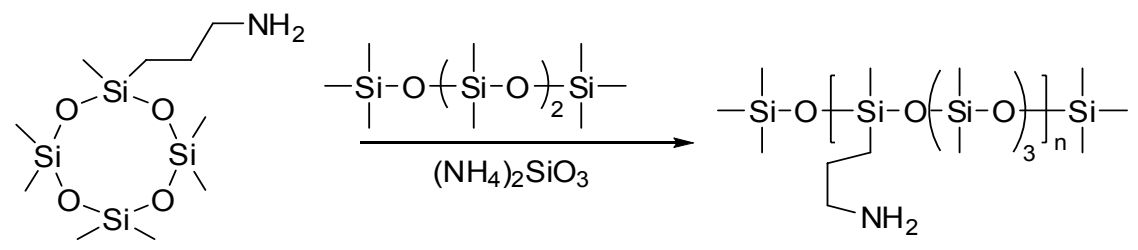

Fig. 9. Functionalization of cyclosiloxane by hydrosilylation and ring-opening polymerization

Directly for the synthesis of polyimides, hydrosilylation can be used in the preparation of a cyclic imide fragment (Figure 10). ${ }^{42}$

In addition, hydrosilylation can be used directly for the attachment of siloxane chains to the imide cycle (Fig. 11)..$^{43}$ In the case where diimide is used (for example, pyromellitic), this approach can be used as an alternative to the method of preparing polyimidesiloxanes through a hydrosilylation reaction.

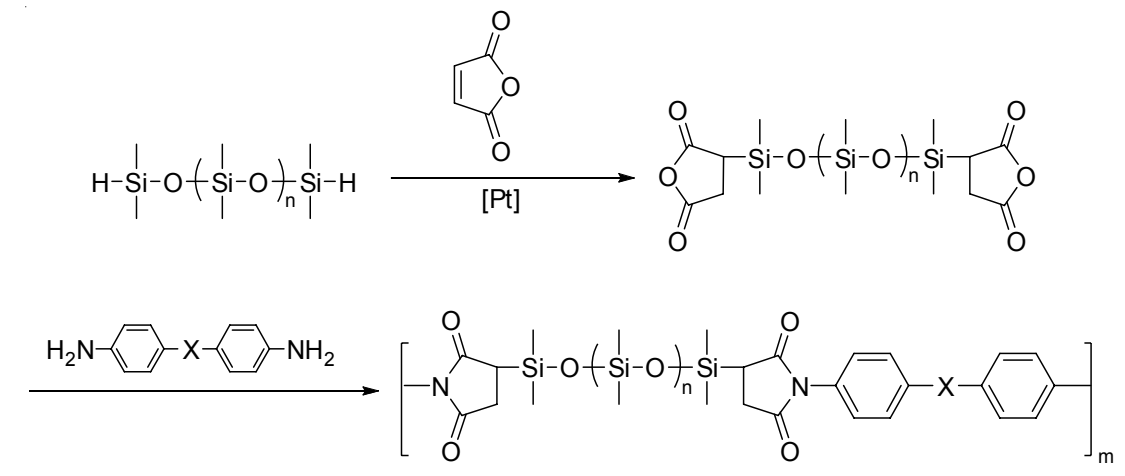

Fig. 10. Hydrosilylation on the double bond of anhydride fragments followed by imidization

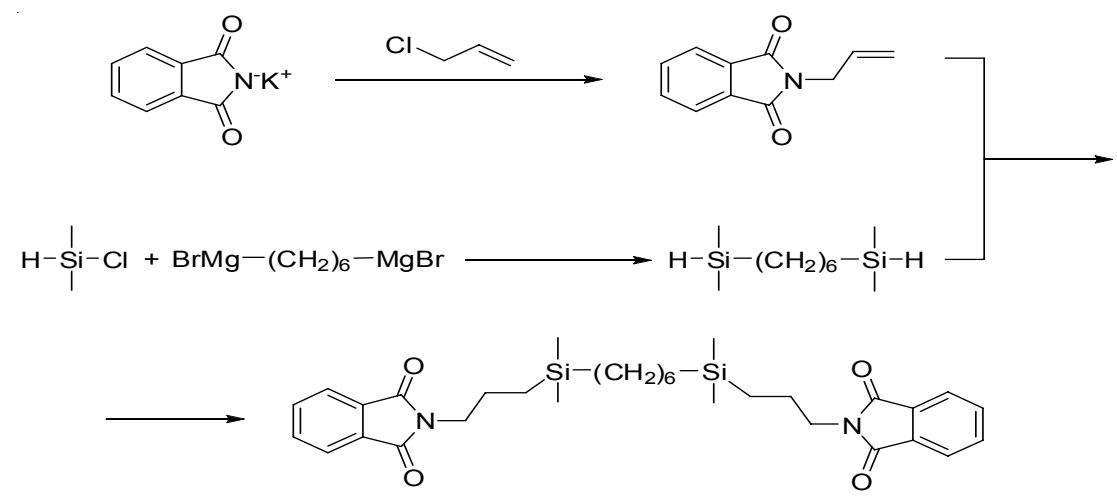

Fig. 11. Hydrosilylation on the double bond of an alkylated imine 
Polyorganosiloxanes modification by chlorosilane condensation

This simple but very effective method for preparing low molecular weight bifunctional siloxanes is based on the condensation reaction of dichlorosilanes with derivatives of alcohols or phenols. Usually this method is applicable for arylsiloxanes in view of greater stability with respect to alkylsiloxanes (Figure 12).

Various diamine derivatives prepared by this method were used to prepare polyimides of various structures. ${ }^{44-48}$ Method of synthesis of the corresponding polyimides with various dianhydride fragments is shown in Figure $13 .{ }^{49}$

Condensation method is also applicable for the modification of the side substituents by amino groups. POSs modified with chloromethyl groups in the side chain are usually used as starting compounds (Figure 14).

There is an alternative method for the preparation of functionalized POS by ring-opening polymerization, originally functionalized by a chloromethyl group. The subsequent stages are similar to the previous approach (Figure 14). ${ }^{50}$<smiles>C[Si](Cl)(Cl)c1ccccc1</smiles>

Fig. 12. Preparation of bifunctional amines by condensation with dichlorosilane

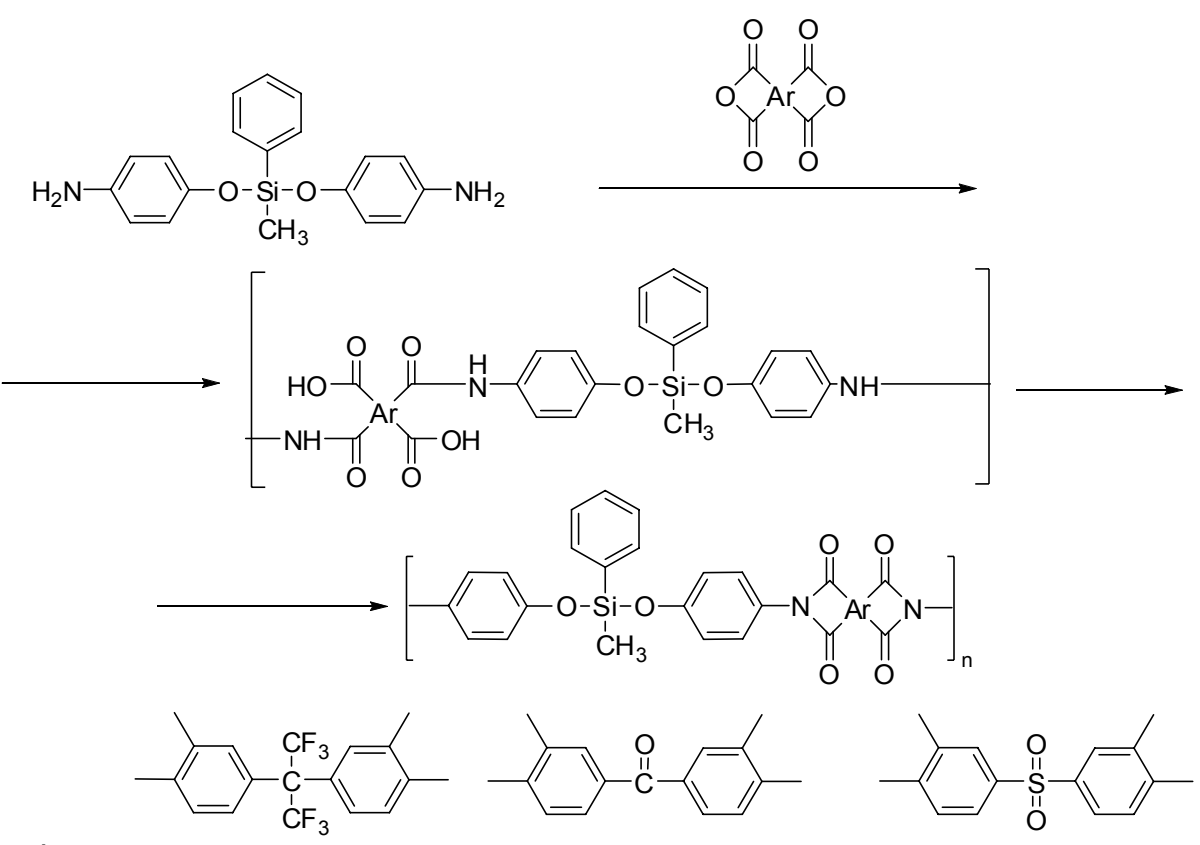
Ar:<smiles>Cc1cc(C)c(C)cc1C</smiles><smiles>Cc1ccc(-c2ccc(C)c(C)c2)cc1C</smiles><smiles>Cc1ccc(Oc2ccc(C)c(C)c2)cc1C</smiles>

Fig. 13. Preparation of polyimides based on siloxane diamine and various dianhydrides 


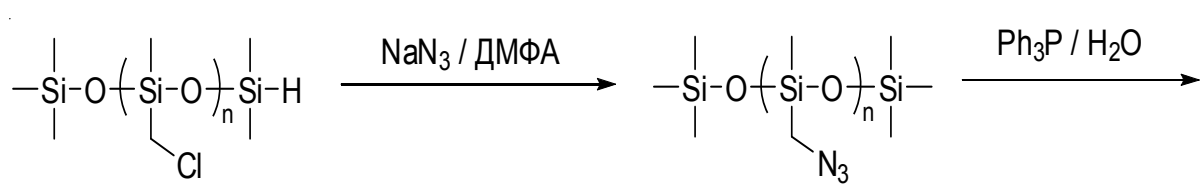

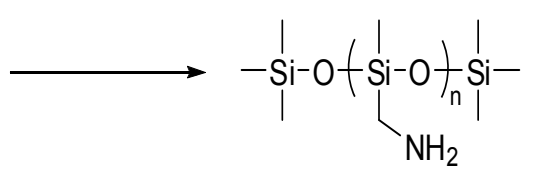

Fig. 14(a). Method for modification of the side chloromethyl groups of POS

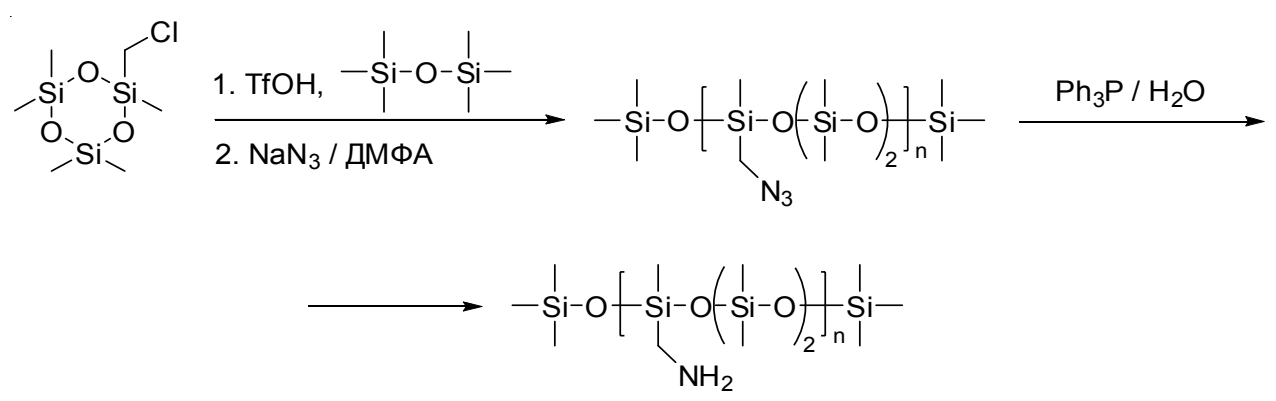

Fig. 14(b). Method for POS modification by amino groups through the cyclosiloxane opening

\section{CONCLUSION}

The main methods for the preparation of oligomeric polysiloxanes containing amino groups are considered. Modified polysiloxanes are the starting compounds for the synthesis of polyimide and polysiloxane copolymers obtained by polycondensation of diamines with aromatic dianhydrides of tetracarboxylic acids. The copolymers are used as a material for protonconducting membranes of fuel cells.

\section{ACKNOWLEDGEMENT}

Applied researches are carried out with state financial support represented by the Ministry of Education of Russia under the Agreement on granting subsidies No. 14.625.21.0036 of October 27, 2015. Unique identifier for Applied Scientific Researches (project) RFMEFI62515X0036.

\section{REFERENCES}

1. Savadogo, O. J. Power Sources., 2004, 127, 135-161.

2. Zhang, X.; Guo, J.; Chen, J. Energy., 2010, 35, 5294-5299.

3. Carton, J. G.; Olabi, A. G. Energy., 2010, 35, 2796-2806.

4. Leo, T. J.; Durango, J. A.; Navarro, E. Energy., 2010, 35, 1164-1171.

5. Ramousse, J. L.; Lottin, O.; Didierjean, S.; Maillet, D. J. Power Sources., 2009, 192, 435-441.

6. Roy, A.; Lee, H. S.; McGrath, J. E. Polymer., 2008, 49, 5037-5344.

7. Wang, S.; McGrath, J. E. Synthesis of poly(arylene ether)s. In: Rogers, M. E.; Long, T. E, editors. Synthetic methods in stepgrowth polymers. New York: Wiley; 2003, 327-374.

8. Miyake, J.; Miyatake, K. Polymer J., 2017, 49, 487-495.

9. Li, N.; Guiver, M. D. Macromolecules., 2014 , 47, 2175-2198.

10. Kreuer, K.-D. Chem. Mater., 2014, 26, 361-380.

11. Liu, Y.-L. Polymer Chem., 2012, 3, 1373-1383.

12. Wilson D, Stenzenberger HD, Hergenrother PM (eds) Polyimides. Blackie, Glasgow, 1990. 
13. Chen, S.; Yin, Y.; Kita, H.; Okamoto, K. I. J. Polym. Sci. Part A Polym Chem., 2007, 45, 2797-2811.

14. Fang, J.; Zhai, F.; Guo, X.; Xu, H.; Okamoto, K. J. Mater. Chem., 2007, 17, 1102-1108.

15. Lee, C. H.; Park, C. H.; Lee, Y. M. J. Membr. Sci., 2008, 313, 199-206.

16. Miyatake, K.; Yasuda, T.; Watanabe, M. J. Polym. Sci. Part A Polym. Chem., 2008, 46, 4469-4478.

17. Lee, C. H.; Chen, J. R.; Shiu, H. W.; Ho, K. S.; Wu, S. D.; Hsieh, K. H.; Wang, E. Z. J. Fuel Cell Sci. Technol., 2010, 7, 021023-1/6.

18. Tseng, J.-Y.; Ye, Y. S.; Hwang, B.-J. ECS Transactions., 2010, 33, 845-853.

19. Gong, C.; Liang, Y.; Qi, Z.; Li, H.; Wu, Z.; Zhang, Z.; Zhang, S.; Zhang, X.; Li, Y. J. Membrane Sci., 2015, 476, 364-372.

20. Lee, C. H.; Chen, J. R.; Shiu, H. W.; Ho, K. S.; Wu, S. D.; Hsieh, K. H.; Wang, Y. Z. J. Fuel Cell Sci. Tech., 2010, 7, 021023-021026.

21. Jones, R. G. Silicon-Containing Polymers. The Royal Society of Chemistry; Cambridge 1995.

22. Zeigler, J. M.; Fearon, F. W. G. Silicon-Based Polymer Science. The American Chemical Society; Washington DC 1990.

23. Chojnowski, J. J. Inorg. Organomet. Polym., 1991, 1, 299-323.

24. Rashkov, I.; Gitsov, I.; Panayotov, I. Polym. Bull., 1983, 10, 487-490.

25. Rashkov, I.; Gitsov, I. J. Polym. Sci. Part A Polym. Chem., 1986. 24, 155-165.

26. Sigwalt, P. Polym. J. 1987, 19, 567-580.

27. Xia, Y.; Cao, D.; Sun, Y.; Li, F.; Qi, Z. Glass Phys. Chem., 2016, 42, 307-311.

28. Gilbert, A. K.; Kantor, S. W. J. Polym. Sci. Part A Polym. Chem., 1959. 40, 35-38.

29. Noll, W. Chemistry and technology of silicones. Academic Press, New York, 1968.

30. Rochow, E. G. Silicon and silicones. Springer, Berlin Heidelberg New York. 1987.

31. Sormani, P. M.; McGrath, J. E. Kinetics and mechanisms of the anionic ring opening polymerization of cyclosiloxanes in the presence of bis(1,3-aminopropyl tetramethyldisiloxane) In: McGrath, J. E. (ed) Ring opening polymerization: kinetics mechanisms and synthesis. ACS Symposium Series No 286, 1985.

32. McGrath, J. E.; Sormani, P. M.; Elsbernd, C. S.; Kilic, S, Makromol Chem Macromol Symp., 1986, 6, 67-80.
33. Hoffman, J. J.; Leir, C. M. Polym. Int., 1991, 24, 131-138.

34. Riffle, J. S.; Yilgor, I.; Tran, C.; Wilkes, G. L.; McGrath, J. E.; Banthia, A. K. in Elastomeric Polysiloxane Modifiers for Epoxy Net-works: Synthesis of Functional Oligomers and Network Formations Studies in Epoxy Resin Chemistry, 2nd edn, ed. by R.S. Bauer, ACS Symposium Series 221, ACS, Washington, 1983.

35. Chojnowski, J.; Rozga K. J. Inorg. Organomet. Polym., 1992, 2, 297-317.

36. Lukevics, E. Russ. Chem. Revs. 1977, 46, 264-277.

37. Cypryk, M.; Pospiech, P. Chemik., 2013. 67, 1173-1180.

38. Lee, V.Ya. Organosilicon Compounds 1st edn. Theory and Experiment (Synthesis). Elsevier, 2017.

39. El-Nahhal, I. M.; Parish, R. V. J. Organomet. Chem., 1993. 452, 19-22.

40. Saam, J. C.; Spier, J.L. J. Org. Chem., 1959, 24, 119-120.

41. Marzinke, M.; MacMillan, J. H.; August, T. F.; Telepchak, M. J. Patent USA, no. US6177583B1. 2001.

42. Kanak, S.; Bisaria, C. S.; Saxena, A. K. Appl. Organomet. Chem., 2009, 23, 535-540.

43. Daiss, J. O.; Duda-Johner, S.; Burschka, C.; Holzgrabe, U.; Mohr, K.; Tacke, R. Organometallics., 2002, 21, 803-811.

44. Keohan, F.L.; Hallgren, J.E. Adv Chem Ser 224 (Silicon-Based Polym Sci)., 1989, 224, 165-179.

45. Summers, J.D.; Elsbernd, C.S.; Sormani, P.M.; Brandt, P. J. A.; Arnold, C.A.; Yilgor, I.; Riffle, J.S.; Kilic, S.; McGrath, J. E. ACS Symposium Series 360, 1988, 180-198.

46. Arnold, C. A.; Summers, J. D.; Chen, Y. P.; Bott, R.; Chen, D.; McGrath, J. E. Polymer., 1989, 30, 986-995.

47. Arnold, C. A.; Summers, J. D.; Bott, R. H.; Taylor, L. T.; Ward, T. C.; McGrath, J. E. SAMPE Proceedings., 1987, 32, 586.

48. Arnold, C. A.; Summers, J. D.; Bott, R. H.; Taylor, L. T.; Ward, T. C.; McGrath, J. E. Polym Preprints, ACS National Meeting., 1987, 28, 217.

49. Liaw, D.-J.; Yang, W.-C. O.; Jong, L.; Yang, M.H. J. Appl. Polym. Sci., 1997, 63, 369-376.

50. Brase, S.; Gil, C.; Knepper, K.; Zimmermann, V. Angew. Chem. Int. Ed., 2005, 44, 51885240 . 